Savunma Bilimleri Dergisi

The Journal of Defense Sciences

Kasim / November 2021, Say1/Issue 40.

ISSN (Bas111) : 1303-6831 ISSN (Online): 2148-1776

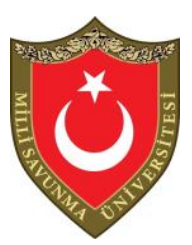

\title{
Mikrodenetleyici Tabanlı Bir Elektronik Kapsül Ateşleme Sistemi Tasarımı
}

\author{
Serkan GÜRKAN*, Emre AYTAV**, Mustafa KARAPINAR ${ }^{* * *}$, \\ Mevlana Halit ALDEMIR ${ }^{* * * *}$
}

$\ddot{O} z$

Elektrikli ateşleme yöntemi kullanılarak, düşük maliyetli, mikrodenetleyici tabanlı bir test ve ateşleme sistemi tasarlanmış ve istem dışı ateşlemeleri önleme kapasitesine sahip bir prototip üretimi gerçekleştirilmiştir. Gelişsirilen prototip, Makine ve Kimya Endüstrisi Kurumu tarafindan imal edilen alüminyum elektrikli kapsüllere eşdeğer elektronik bileşenler ve eğitim kapsülleri ile fonksiyonel testlere tabi tutulmuştur. 3 adet AA lityum pille çalışan kapsül ateşleme sistemi, $8 \mathrm{Ws} / \Omega$ çıkış enerjisi üreterek art arda 700 ayr ateşleme gerçekleştirebilir. Ayrıca sistem

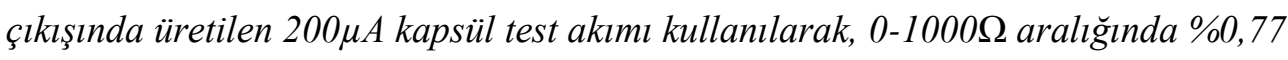
ortalama toleransla kapsül direnci testleri yapılabilir. Geliştirilen sistemin özellikle patlayıc madde keşif ve imha timlerinin kullanımına uygun olduğu değerlendirilmektedir. Elektronik kapsül ateşleme sisteminde kontrol dışı ateşlemeleri önlemek maksadıyla sistem çıkışında düşük test akımı oluşturulur. Ayrıca kapsül emniyetini sağlamak maksadıyla, ateşlemeden vazgeçme ve sistem boşta bekleme durumlarında tahrip enerjisinin hızlı şekilde boşaltılması için tedbirler alınmıştır. Merkezi işlem birimi olarak Atmega328 mikrodenetleyicisi tercih edilmiş ve geliştirilen gömülü yazılım ile sistemdeki bütün kontrollerin

*Dr.Öğr.Üyesi, Milli Savunma Üniversitesi, Kara Astsubay MYO, Elektronik Haberleşme Teknolojisi Bölümü, sgurkan@msu.edu.tr, ORCID: 0000-0003-2229-3361

**Dr.Öğr.Üyesi, Milli Savunma Üniversitesi, Kara Harp Okulu, Makine Mühendisliği Bölümü, eaytav@kho.edu.tr, ORCID: 0000-0003-4296-6703

*** Öğ.Gör., Milli Savunma Üniversitesi, Kara Astsubay MYO, Elektronik Haberleşme Teknolojisi Bölümü, mkarapinar@gmail.com, ORCID: 0000-0002-1953-6804

**** Öğ.Gör., Milli Savunma Üniversitesi, Kara Astsubay MYO, Elektronik Haberleşme Teknolojisi Bölümü, m.halitaldemir@gmail.com, ORCID: 0000-0003-0228-5145

Geliş Tarihi/Received : 14.12 .2020

Kabul Tarihi/Accepted : 09.06.2021

Araştırma Makalesi/Research Article DOI: 10.17134/khosbd.1001194 
gerçekleştirilmesi sağlanmıştır.

Anahtar Kelimeler: Ateşleyici, Patlayıcı Madde İmhası, Elektronik Kapsül Ateşleme Sistemi, Balistik.

\title{
Design of a Microcontroller Based Electronic Detonator Ignition System
}

\begin{abstract}
A low-cost, microcontroller-based test and ignition system has been designed using the electrical ignition method, and a prototype capable of preventing unintentional ignitions has been produced. The developed prototype was subjected to functional tests with electronic components and training detonators equivalent to aluminum electric detonators manufactured by the Machine and Chemical Industry Corporation. The detonator ignition system powered by 3 AA lithium batteries can perform 700 separate ignitions consecutively by generating $8 \mathrm{WS} / \Omega$ output energy. In addition, detonator resistance tests can be performed in the range of 0-1000 $\Omega$ with a tolerance of $0.77 \%$ by using the $200 \mu \mathrm{A}$ detonator test current generated at the system outlet. The developed system is considered to be particularly suitable for use by explosives reconnaissance and destruction teams. In order to prevent uncontrolled ignitions in the electronic detonator ignition system, a low test current is created at the system outlet. Furthermore, in order to ensure the safety of the detonator, precautions were taken for the rapid and safe discharge of destructive energy in cases of cancelling the ignition and idling process. Atmega328 microcontroller has been preferred as the central processing unit, and it has been ensured that all controls in the system were carried out with the developed embedded software.
\end{abstract}

Keywords: Detonator, Explosive Ordnance Disposal, Electronic Detonator Ignition System, Ballistic.

\section{Giriş}

Patlayıcılar, katı haldeyken kısa sürede gaz haline geçebilen, bu geçiş esnasında yüksek miktarlarda 1sı, şok ve ses ile etrafta fiziksel etkiler oluşturabilen kimyasal maddelerdir (Özdikmen, 2009). Patlayıcılar, sivil ve askerî alanda birçok alanda kullanılmaktadır. Sivil alanda; maden ocaklarının açılması, büyük yapılarda 
ve barajlarda tahribat işlemleri en sık karşılaşılan uygulamalardır. Askerî alanda ise; geçitlerin açılması, belirlenen hedeflerin tahrip edilmesi gibi uygulamalarla karşılaşılmaktadır. Patlayıcıların yasal olarak kullanımının yanı sıra terör grupları tarafindan yasadışı kullanımı da söz konusudur. Türkiye Cumhuriyeti'nde, patlayıcıların üretimi, ambalajlanması, taşınması, saklanması, depolanması, ithali, satışı, kullanılması, yok edilmesi, denetimi gibi hususlar 87/12028 sayılı "Tekel Dışı Bırakılan Patlayıcı Maddelerle Av Malzemesi ve Benzerlerinin Üretimi, İthali, Taşınması, Saklanması, Depolanması, Satışı, Kullanılması, Yok Edilmesi, Denetlenmesi Usul ve Esaslarına İlişkin Tüzük” ile belirlenmiştir.

Uygulama alanında patlayıcıyı harekete geçirmek ve böylelikle beklenen 1s1, şok ve ses etkisini ortaya çıkarmak için ateşleyicilere (detonatör) ihtiyaç vardır. Ateşleyici, patlayıcı endüstrisinde patlamayı başlatmak için kullanılan aygıtı tanımlamak için kullanılan bir terimdir (Pande, Kumar ve Singh, 2015). Uygulamalarda patlayıcıları harekete geçirmek için farklı tip ateşleyiciler kullanılabilir (Bickes Jr., 1996). Yakma tipi ateşleyicilerde, emniyetli fitil ve düşük miktarlarda patlayıcı ihtiva eden patlayıc madde (yemleme) kullanılır. Bir metre fitilin takriben kaç saniyede yandığ gözlemlenir, ihtiyaç duyulan zaman gecikmesine bağlı olarak uygun fitil boyu belirlenir, fitilin bitiş noktasında bulunan ana patlayıcının üzerine daha az miktarlarda patlayıcı içeren kapsül yerleştirilir. Son işlem olarak fitilin ucu ateşlenir ve belirlenen süre sonunda önce kapsülde ardından da ana patlayıcıda ateşleme gerçekleşir. Ancak bu yöntemde, belirlenen süre ile ateşlemenin gerçekleşme süresi arasında önemli farklar olabilir. Bu yöntemin en önemli mahsuru, güvenilir olmayan gecikme süresidir. Bu sebeple, özellikle zamanlamanın önemli olduğu ardışık ateşleme işlemlerinde tercih edilmezler. Bunun yanı sıra, zamanlamanın çok önemli olmadığı, tekil ateşleme işlemleri için ekonomik ve nispeten emniyetli bir çözüm sunar (Jadhav ve Patil, 2016). Ateşlemede kullanılan diğer yöntem de şok tüpüdür. Şok tüpü, elektriksel olmayan, anlık sinyal iletim sistemidir ve elektrikli kapsülleri ateşlemek için kullanılır. Bu yöntemde şok sinyali, iç yüzeyi ince film kaplı reaktif malzeme boyunca ilerler ve ulaştı̆̆ noktada meydana getirdiği piezoelektrik etki ile ateşlemeyi gerçekleştirir (Konya, 1995). Ateşleme anında elektriksel etmenlerden etkilenmedikleri için emniyetli bir çözüm sunar. Ateşleme düzeneğinin karmaş1k olması ve yüksek maliyetli olması önemli mahsurları arasındadır. Düşük maliyeti, sürdürülebilirliği ve kullanım kolaylıkları nedeniyle askerî uygulamalarda en sık tercih edilen yöntem elektrik ile ateşleme 
yöntemidir (EAY) (Beveridge, 2013). Bu yöntem ile elektrikli ateşleyicilerin tahrip edilmesi için ihtiyaç duyulan elektrik enerjisi sağlanır ve istenilen süre sonunda veya ateşleme enerjisi eşiği aşıldığında, üretilen enerji kapsül üzerine uygulanır ve ateşleme gerçekleştirilir. Yukarıda bahsedilen bütün yöntemlerde olduğu gibi, EAY'nin de bazı mahsurları vardır. Bu mahsurların içerisinde en önemlisi kaçak elektrik akımlarıdır. Kaçak elektrik akımları, radyo frekans sinyallerinden, manyetik alanlardan, statik elektrik alanlarından kaynaklanabilir ve elektrikli ateşleyicinin istem dışı ateşlenmesine sebep olabilir. Ancak, tüm yöntemlerde olduğu gibi bu yöntemde de mahsurların bilinip, sistem tasarımında gerekli tedbirlerin alınması önem arz eder.

EAY'nin kullanıldığı elektronik kapsül ateşleme sistemleri (EKAS) daha önce çalışılmış bir konudur. Bu çalışmaların sonucunda ortaya çıkan ve patlayıcı madde keşif ve imha (EOD) timlerinin hâlihazırda harekât sahasında kullanmış olduğu ticari EKAS'leri mevcuttur. Bu ürünlerden en sık kullanılanlarına ait bazı özellikler Tablo 1'de verilmiştir.

Tablo 1. EOD Timleri Tarafindan Kullanılan Ticari EKAS'larden Bazılarının Özellikleri

\begin{tabular}{|c|c|c|c|c|c|c|c|}
\hline $\begin{array}{c}\text { Marka/ } \\
\text { Model }\end{array}$ & $\begin{array}{c}\text { Ateşleme } \\
\text { Gerilimi } \\
(\mathrm{V})\end{array}$ & $\begin{array}{c}\text { Ateşleme } \\
\text { Enerjisi } \\
(\mathrm{Ws} / \Omega)\end{array}$ & $\begin{array}{c}\text { Kapsül } \\
\text { Testi } \\
\text { Aralığ1 } \\
(\Omega)\end{array}$ & $\begin{array}{c}\text { Kapsül } \\
\text { Test } \\
\text { Akım1 } \\
(\mu \mathrm{A})\end{array}$ & $\begin{array}{c}\text { Tekil } \\
\text { Ateşleme } \\
\text { Sayıs1 }\end{array}$ & $\begin{array}{c}\text { Ağıllık } \\
(\mathrm{gr})\end{array}$ & $\begin{array}{c}\text { Fiziksel } \\
\text { Ölçüler } \\
(\mathrm{mm})\end{array}$ \\
\hline $\begin{array}{c}\text { Mini- } \\
\text { Shrike } \\
\text { (MINI- } \\
\text { SHRIKE } \\
\text { 2018) }\end{array}$ & 400 & 8,0 & $0-400$ & 500 & 100 & 240 & $151 \times 58 \times 46$ \\
\hline $\begin{array}{c}\text { PED Mk2 } \\
\text { (PED- } \\
\text { MK2 } \\
\text { 2018) }\end{array}$ & 300 & 1,5 & - & 750 & 100 & 100 & $103 \times 38 \times 30$ \\
\hline $\begin{array}{c}\text { Detomax } \\
\text { JK } \\
\text { (Detomax } \\
2020)\end{array}$ & 400 & 7,5 & $0-999$ & 250 & 700 & 230 & $120 \times 69 \times 24,5$ \\
\hline
\end{tabular}

$\mathrm{Bu}$ çalışmada; EAY'nin kullanıldığı, istem dışı ateşlemelerin gerçekleşmemesi için gerekli tedbirlerin alındığ 1 , düşük maliyetli, mikrodenetleyici 
tabanlı bir test ve ateşleme sistemi tasarlanmış ve prototip üretimi gerçekleştirilmiştir. Geliştirilen prototip Makine ve Kimya Endüstrisi Kurumu (MKEK) tarafından imal edilen alüminyum elektrikli kapsüle eşdeğer elektronik bileşenler ve eğitim kapsülleri ile fonksiyon testlerine tabi tutulmuştur. Çalışma sonucunda; 3 adet AA Lityum pil beslemeli, art arda 700 adet tekil ateşleme gerçekleştirebilen, $0-1000 \Omega$ aralığında $\% 0,77$ toleransla kapsül direnci testi yapabilen, kapsül test akımı $200 \mu \mathrm{A}$ olan, $8 \mathrm{Ws} / \Omega$ ateşleme enerjisi üretebilen bir EKAS geliştirilmiştir. Geliştirilen ürünün özellikle EOD timleri tarafından kullanımına uygun olduğu değerlendirilmektedir. Geliştirilen EKAS'de kontrol dışı ateşlemeleri önlemek maksadıyla düşük test akımı oluşturulmuştur. Yine kapsül emniyetini sağlamak maksadıyla, ateşlemeden vazgeçme ve sistem boşta bekleme durumlarında tahrip enerjisinin hızlı şekilde boşaltılması için tedbirler alınmıştır.

\section{Elektrikli Kapsüller ve Elektriksel Özellikleri}

\section{a. Elektrikli Kapsüller}

Elektrikli kapsüller; elektrik ile ateşlenebilen, içerisine kibritbaşı yerleştirilmiş ateşleyicilerdir. Elektrikli kapsüllerin ateşlenmesinde enerji kaynağ 1 olarak batarya kullanılabileceği gibi, ardışık ve emniyetli ateşlemeler için EKAS tercih edilir (Özcan, 2006). Elektrikli kapsüle ait basitleştirilmiş yapı ve görünümler Şekil 1'de verilmiştir.

Elektrikli kapsülün ateşlenmesi ile amaçlanan, PETN/TETRIL'in ateşlenmesi ve bununla beraber asıl ateşlenmek istenen TNT kalıbı gibi patlayıcıların infilak etmesi için ihtiyaç duyulan enerjinin açığa çıkarılmasıdır (Zhang, 2016). Kibritbaşı birkaç amper akım ile ateşlenebilen kimyasallardır. Kibritbaşının ateşlenmesi ile açığa çıkan enerji TNT veya PETN/TETRIL'i doğrudan ateşlemek için yetersizdir. $\mathrm{Bu}$ yüzden kibritbaşından açığa çıkan enerji öncelikle kurşun azodür/civa fülminatı ateşler. Ardından önce PETN/TETRIL ve nihai olarak TNT kalıbı ateşlenmiş olur (Solov'ev vd., 2015).

MKEK tarafindan üretilen ve Şekil 1(b) ve Şekil 1(c) de görselleri verilen iki farklı tipteki elektrikli kapsüle ait temel özellikler Tablo 2'de verilmiştir (MKEK, 2020). Veriler incelendiğinde; elektrikli bakır ve alüminyum kapsüllerin aynı sınıf ürünleri için ateşleme parametrelerinin aynı olduğu görülmektedir. 

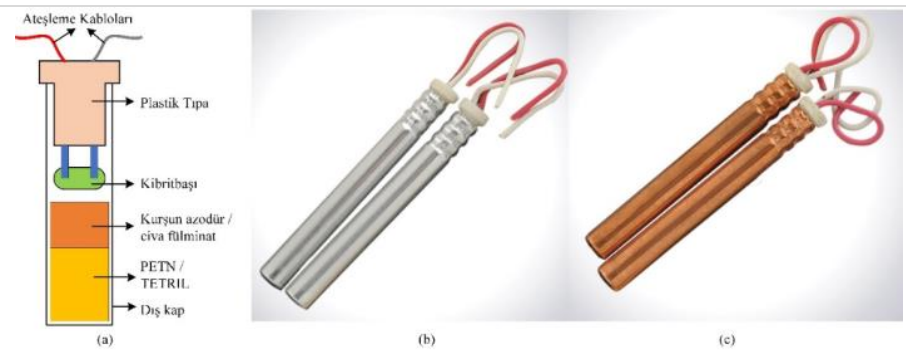

Şekil 1. (a) Elektrikli Kapsülün Basitleştirilmiş Yapısı (b) Alüminyum Dış Kaplı Elektrikli Kapsül (c) Bakır Dış Kaplı Elektrikli Kapsül

Tablo 2. MKEK Tarafından Üretilen Elektrikli Kapsüllerin Özellikleri

\begin{tabular}{|c|c|c|c|c|c|c|}
\hline $\begin{array}{c}\text { Elektrikli } \\
\text { Kapsül Tipi }\end{array}$ & Sınıf & $\begin{array}{c}\text { Kibritbaşı } \\
\text { direnci } \\
(\Omega)\end{array}$ & $\begin{array}{c}\text { Ateşlenme } \\
\text { Darbe } \\
\text { Enerjisi } \\
\mathrm{mWs} / \boldsymbol{\Omega}\end{array}$ & $\begin{array}{c}\text { Ateşlenmeme } \\
\text { Darbe Enerjisi } \\
\mathrm{mWs} / \boldsymbol{\Omega}\end{array}$ & $\begin{array}{c}\text { Emniyet } \\
\text { Sinırı } \\
(\mathrm{A})\end{array}$ & $\begin{array}{c}\text { Ateşlenme } \\
\text { Akımı } \\
(\mathrm{A})\end{array}$ \\
\hline \multirow{2}{*}{ Alüminyum } & 1 & $1,2-1,8$ & 3 & 0,8 & 0,18 & 1 \\
\cline { 2 - 7 } & 2 & $0,4-0,8$ & 16 & 2,8 & 0,45 & 1,5 \\
\hline \multirow{2}{*}{ Bakır } & 1 & $1,2-1,8$ & 3 & 0,8 & 0,18 & 1 \\
\cline { 2 - 7 } & 2 & $0,4-0,8$ & 16 & 2,8 & 0,45 & 1,5 \\
\hline
\end{tabular}

Sınıf-1 elektrikli kapsüllerin 1 A akımdan itibaren ateşlendiği ve 3 $\mathrm{mWs} / \Omega$ 'luk enerjiye ihtiyaç duyduğu görülmektedir. $0,18 \mathrm{~A}$ akım ve $0,8 \mathrm{mWs} / \Omega$ 'luk enerjinin altındaki değerlerde sınıf-1 kapsülün ateşlenmediği görülmektedir. 0,18 A ile $1 \mathrm{~A}$ akım değerleri ve $0,8 \mathrm{mWs} / \Omega$ ile $3 \mathrm{mWs} / \Omega$ enerji aralıkları sınıf- 1 elektrikli kapsüller için kararsız bölgedir. Bu bölgede sınıf-1 elektrikli kapsülün ateşlenmesi veya ateşlenmemesi garanti edilemez. Benzer şekilde, sınıf-2 elektrikli kapsüllerin 1,5 A akımdan itibaren ateşlendiği ve $16 \mathrm{mWs} / \Omega$ 'luk enerjiye ihtiyaç duyduğu görülmektedir. $0,45 \mathrm{~A}$ akım ve $2,8 \mathrm{mWs} / \Omega$ 'luk enerjinin altındaki değerlerde sınıf2 kapsülün ateşlenmediği görülmektedir. 0,45 A ile 1,5 A akım değerleri ve 2,8 $\mathrm{mWs} / \Omega$ ile $16 \mathrm{mWs} / \Omega$ enerji aralıkları sınıf-2 elektrikli kapsüller için kararsız bölgedir. Bu bölgede sınıf-2 elektrikli kapsülün ateşlenmesi veya ateşlenmemesi garanti edilemez.

Emniyetli bir EKAS'dan beklenen en önemli özellik, kararsız bölgelerin dışında akım ve enerji sağlamasıdır. Bu kapsamda; ateşleme esnasında ihtiyaç duyulan akım ve enerji değerinin olabildiğince üzerinde, bekleme ve test durumlarında emniyet sınırlarının olabildiğince altında akım ve enerji üretilmesi önemlidir. 


\section{b. Elektrikli Kapsüllerin Elektriksel Özellikleri}

Elektrik enerjisinin kapsüle uygulanması, ateşleme kablolarından geçen akım geçişi, kibritbaşını tutan iletkenin 1sınması, kibritbaşının yeteri kadar 1sınması, birincil ve ikincil patlayıcıların ateşlenmesi şeklinde meydana gelen ardışık reaksiyon elektrikli kapsülün ateşlenmesini sağlar. $\mathrm{Bu}$ ardışı işlemlerin gerçekleşmesi esnasında bir zaman gecikmesinin yaşanması beklenir. Kapsüle enerji verilmesi ile kibritbaşının ateşlenmesi arasında geçen süre "reaksiyon süresi", birincil patlayııının ateşlenmesi için geçen süre "kopma süresi”, ikincil patlayıcının ateşlenmesi için geçen süre ise "patlama süresi" olarak anılır (Kılıç ve Bağcaz, 2015). Tablo 2'de özellikleri verilen kapsüller için patlama süreleri birkaç milisaniye olduğundan, bu kapsüller gecikmesiz kapsül olarak ifade edilirler. Elektrikli kapsüller üretici firma tarafından belirlenen akım değerinin belli bir süre uygulanması neticesinde patlarlar. Bu akım değeri "ateşlenme akımı" dır. Diğer taraftan kapsülün kesinlikle ateşlenmeyeceği akımı ifade eden değer ise "ateşlenmeme akımı" veya "emniyet sınırı" dır. Elektrikli kapsülün ateşlenmesi için ihtiyaç duyulan enerji miktarı "ateşlenme enerjisi” dir ve Eşitlik 1 ile hesaplanabilir. Eşitlik 1'de E: ateşlenme enerjisi (joule veya watt saniye), V: kapsül gerilimi (Volt), I: akım (amper), t: süre (saniye)'dir.

$$
E=V . I . t
$$

Tablo 2'de verilen özelliklerde anılan sınıf-1 kapsüller "hassas", sınıf-2 kapsüller "duyarsız", Tablo 2'de yer almayan ancak sınıf-3 olarak anılan kapsüller ise "çok duyarsız kapsül" şeklinde de isimlendirilir. Ateşlenme enerjisi kapsüllerin duyarlılıklarını belirlemek için yetersiz kalır. Bu yüzden kapsül birim direnci başına ihtiyaç duyulan enerji miktarını ifade eden "ateşlenme darbe enerjisi" ifadesi kullanılır. Ateşlenme darbe enerjisi Eşitlik 2 veya Eşitlik 3 ile hesaplanabilir. Eşitlik 2'de R: kapsül direnci (Ohm), K: kapsül ateşlenme darbesi enerjisidir (milijoule/ohm veya miliwatt/saniye)'dir.

$$
\begin{aligned}
& K=E / R \\
& K=I^{2} \cdot t
\end{aligned}
$$

Kapsül ateşleme darbesi değeri, kapsül hassasiyeti hakkında fikir oluşmasını sağlar. Küçük K değerine sahip kapsüller hassas, yüksek K değerine sahip kapsüller duyarsız kapsül olarak sınıflandırılır. 


\section{c. Elektronik Kapsül Ateşleme Sistemleri}

EKAS'lar, birden çok elektrikli kapsülün seri, paralel veya karışık bağlantılar ile imhasına olanak tanır. EKAS'larda kapsüle uygulanacak ateşleme darbe enerjisi öncelikle bir kondansatörde depolanır ve arzu edilen zamanda depolanan bu enerji kapsül üzerinden boşaltılarak patlama gerçekleştirilir. Enerji depolama esnasında kapsüle akım akmaması ve kaza önleyici tedbirlerin alınması gereklidir. EKAS'ler kısa sürede, yüksek akımlı enerjiyi kapsüle aktararak gecikmesiz kabul edilebilecek bir patlama gerçekleştirir. Tablo 1'de özellikleri verilen ve değişik firmalara ait EKAS'lerine ait görüntüler Şekil 2'de verilmiştir.
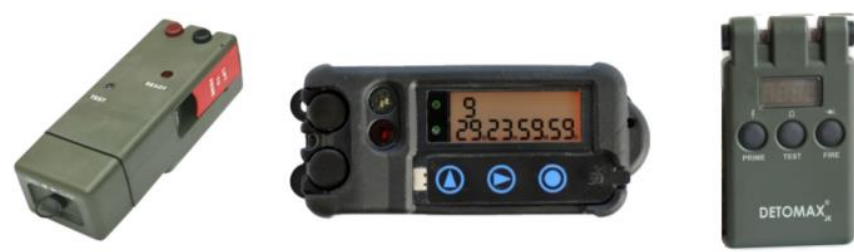

Şekil 2. Ticari Maksatlı Üretilen Birkaç EKAS'lardan Görseli Görüntüler

Enerjiyi depolayan ve kapsüle aktaran kondansatörlerde depolanan enerji miktarı Eşitlik 4'te verildiği gibidir. Eşitlikte 4'te C: EKAS'de kullanılan kondansatörün kapasitesi (Farad) ve V: EKAS'nin çıkış gerilimi (Volt)'dir.

$$
E=\frac{1}{2} C \cdot V^{2}
$$

Deşarj durumundaki kondansatörün herhangi bir andaki enerji miktarı ise Eşitlik 5 ile hesaplanabilir. Eşitlik 5'te E(t): herhangi bir andaki kondansatör enerjisi (joule veya watt saniye), E0: kondansatörün başlangıç enerjisi (joule veya watt saniye), R: yük direnci (Ohm), C: kondansatörün kapasitesi (Farad), t: zaman (saniye)'dır.

$$
E(t)=E_{0} \cdot e^{-\left(\frac{t}{R \cdot C}\right)}
$$

\section{Sistem Tasarımı}

Tablo 2'de verilen veriler EKAS'ın tasarımını belirleyen en önemli parametrelerdir. $\mathrm{Bu}$ parametreler ve elektrikli kapsülün tahribat öncesi emniyet 
şartları göz önünde bulundurularak gerçekleştirilen EKAS'ın görüntüleri Şekil 3'te, blok şeması Şekil 4'te verilmiştir.

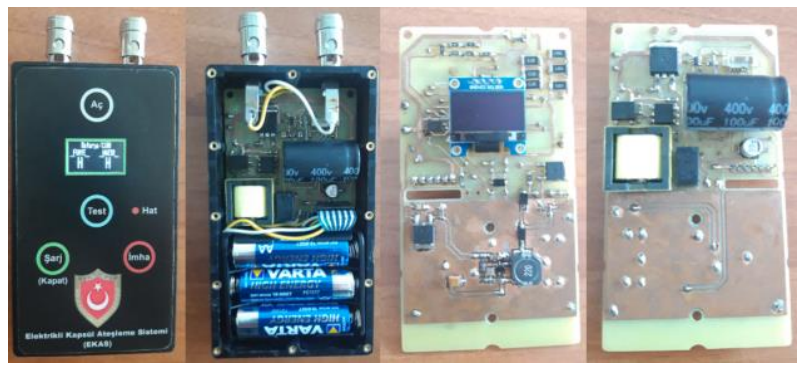

Şekil 3. Tasarlanan Sisteme Ait Görüntüler

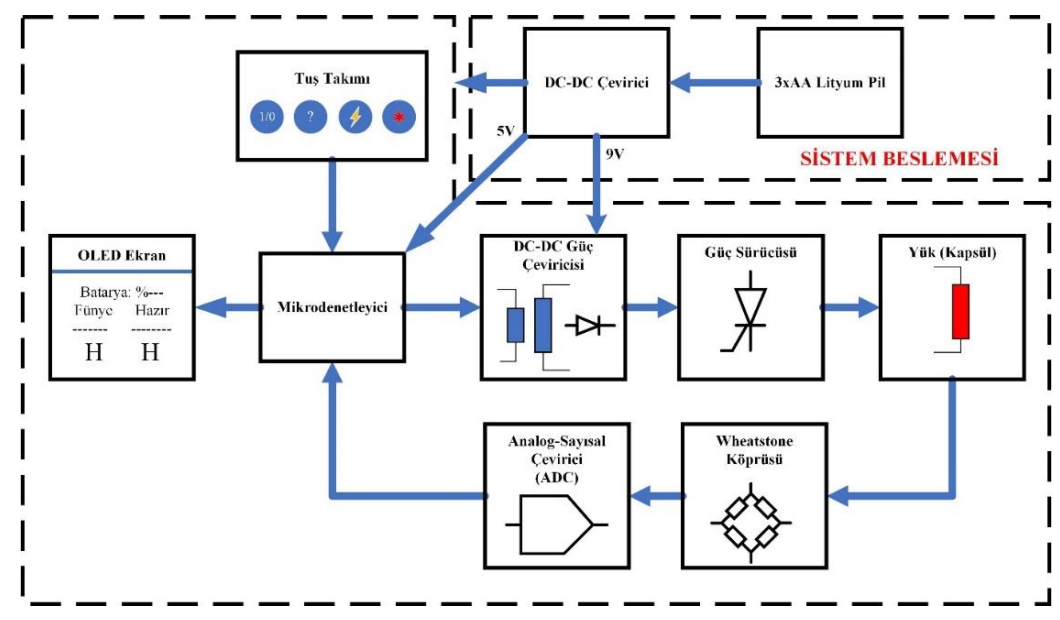

Şekil 4. Tasarlanan Sisteme Ait Blok Şema

Sistem, 3 adet seri bağlı AA lityum pilden aldığı DC gerilimi besleme kaynağı olarak kullanır. Sistem besleme devresi, yükselten tip yalıtımsız DC-DC çevirici ile sabit DC-DC çeviriciden oluşmaktadır. Yalıtımsız DC-DC çevirici girişine uygulanan 4,5V DC gerilimi 9V DC gerilime çevirir. Sabit DC-DC çevirici ise girişine uygulanan 9V DC gerilimi 5V DC gerilime çevirir. 9V DC gerilim elektrikli kapsülü ateşlemek için tasarlanan DC-DC güç çeviricisinde kullanılırken, 5V DC gerilim mikrodenetleyici ve diğer aktif devre elemanlarının ihtiyaç duyduğu gerilimi sağlar. Besleme devresine ait devre şeması Şekil 5 'te verilmiştir. 


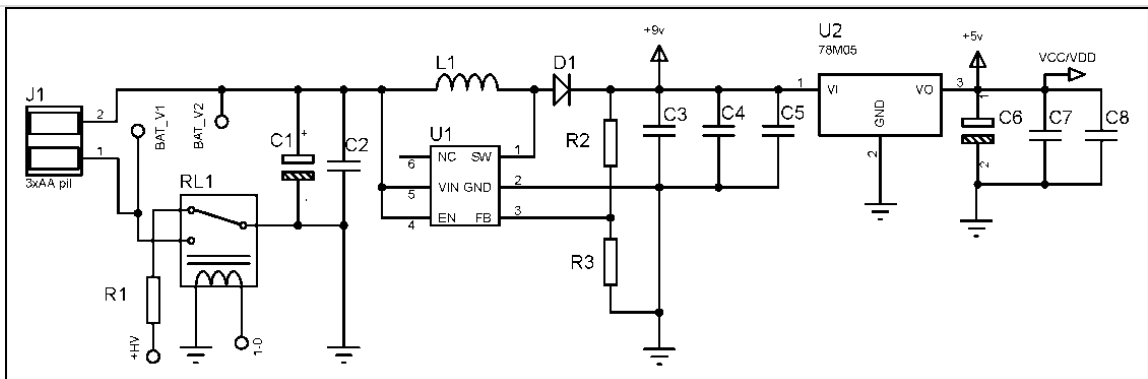

Şekil 5. Sistem Beslemesine Ait Devre Şeması

Merkezi işlem birimi (MIB) olarak Atmega328 mikrodenetleyicisi tercih edilmiştir. Mikrodenetleyici sistemdeki tüm birimlerdeki veri akışını kontrol eder. Sistemin kullanıcı arayüzünde bulunan tuş takımından girilen komutların işlenmesi, kapsül direncinin ölçülmesini sağlayan analogdan sayısala dönüştürücü (ADC) ile iletişim kurulması, kapsül ateşlemede kullanılan yüksek gerilimli sinyalin elde edilmesini sağlayan darbe genişlik modüleli (PWM) sinyali üretilmesi ve kullanıcı arayüzünde bulunan OLED ekranda görüntü oluşturma işlevleri mikrodenetleyicinin başlıca görevleridir. Mikrodenetleyici ile OLED ekran ve ADC bileşenleri arasındaki haberleşme I2C protokolü ile gerçekleştirilmektedir. MIB ve temel çevre birimlerinin devre şemaları Şekil 6'da, Atmega328 mikrodenetleyicisinde işletilen gömülü yazılımın akışşeması ise Şekil 7'de verilmiştir.

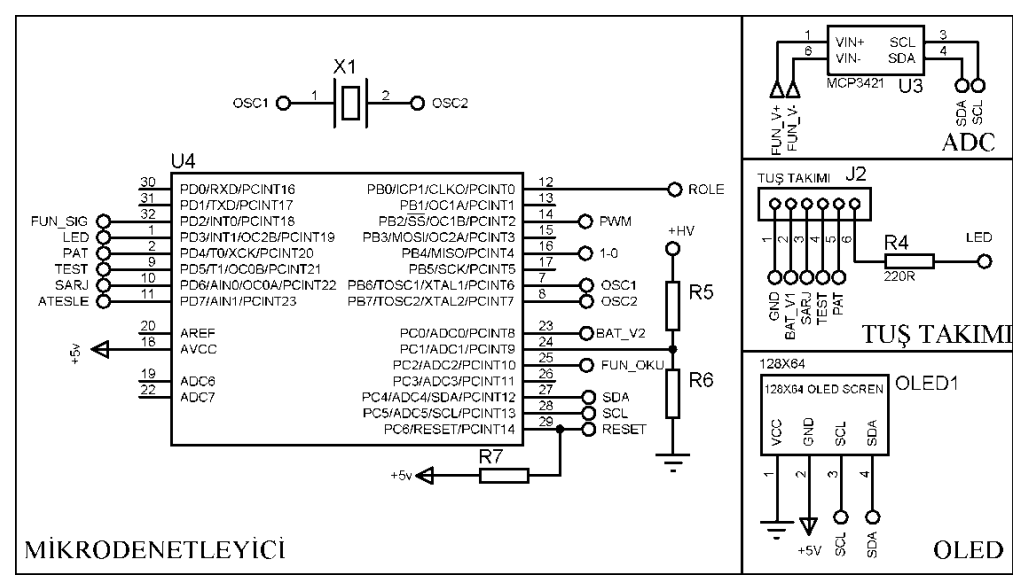

Şekil 6. MiB ve Temel Çevre Birimlerine Ait Devre Şemaları 


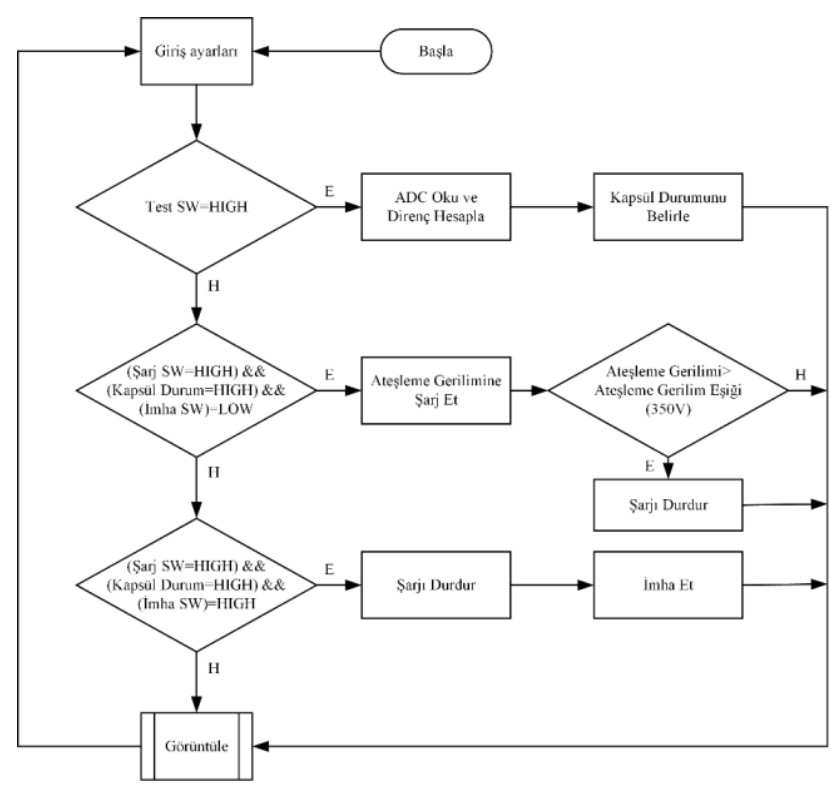

Şekil 7. Atmega328 Mikrodenetleyicisinde Yürütülen Gömülü Yazılımın Akış Şemas1

Kapsül direncinin test edildiği, kapsülün tahrip edilmesi için ihtiyaç duyulan enerjinin elde edildiği ve verilen komut ile kapsülün tahribinin gerçekleştirildiği üniteler Wheatstone köprüsü, DC-DC güç çevirici, güç sürücüsüdür. Bu ünitelere ait devre şemaları Şekil 8'de verilmiştir. R8, Q1, TR1, BR1 ve C9 devre elemanlarından oluşan ünite Flyback tipi bir DC-DC güç çeviricisidir. Mikrodenetleyiciden Q1'in gate ucuna uygulanan PWM sinyali TR1 transformatörünün çıkışında bir alternatif gerilim uluşmasına neden olur. TR1, 1:125 sarım oranına sahip 4VA güç değerine sahip bir transformatördür. Bu gerilim BR1 köprü diyotu ile doğrultularak dalgalı doğru gerilim elde edilir. C9 kondansatörü ise filtreleme işlevini yerine getirerek 400V DC değerine kadar ulaşabilen bir DC gerilim elde edilmesini sağlar. R9, R10, U5, R11, Q2 ve R12 devre elemanlarından oluşan ünite güç sürücü ünitesidir. Kapsül ateşlemesi için elde edilen gerilim Q2 tristörünün anot ucuna uygulanmaktadır. Q2 tristörüne gate tetiklemesi gelmediği sürece kesimdedir. Tahribatın gerçekleşmesi için mikrodenetleyiciden R9'a sayısal "Yüksek" sinyalinin uygulanmasıyla beraber U5 optik yalıtıcıs1 enerjilenir ve Q2'nin tetiklenmesi sağlanır. Böylelikle J3-J4 terminallerine bağlı olan kapsül tahrip edilmiş olur. R13, R14, R15, R16, D2, D3 ve R17 devre elemanlarından oluşan ünite Wheatsone köprüsüdür. Bu devre yapısı 
sayesinde kapsül direnci düşük akımlar ile sağlıklı şekilde test edilebilir. Mikrodenetleyiciden, Wheatstone köprüsüne uygulanan sayısal "Yüksek" test sinyali ile kapsül üzerinden bir akım geçer. Bu akım, A-B noktalarında bir gerilim düşümü oluşmasına sebep olur. A-B gerilimi U3 ADC'si ile sayısala çevrilir ve mikrodenetleyiciye iletilir.

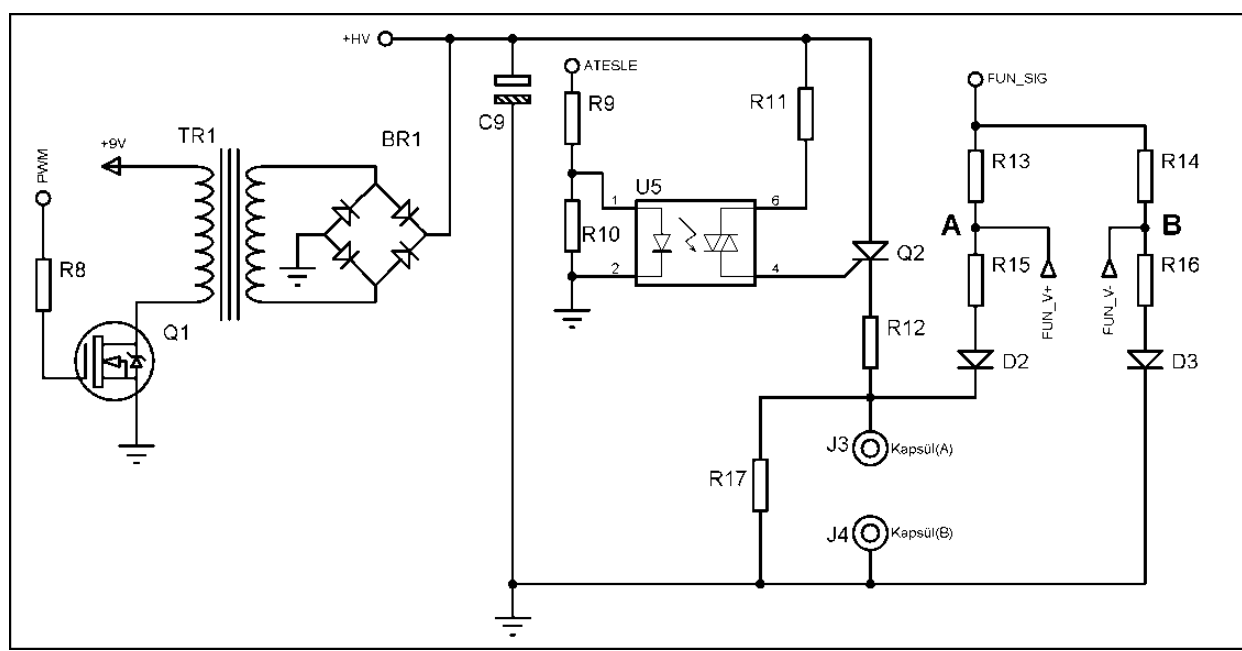

Şekil 8. DC-DC Güç Çevirici, Güç Sürücüsü ve Wheatstone Köprüsü Ünitelerine Ait Devre Şemaları

\section{Deneysel Çalışmalar}

Geliştirilen prototip sistemin işlevlerini ve performansını değerlendirmek maksadıyla bazı deneysel çalışmalar gerçekleştirilmiştir.

\section{a. Şarj-Deșarj Eğrisinin İncelenmesi}

Geliştirilen sistemde, kapsüle aktarılan enerji C9 kondansatöründe depolanmaktadır. Depolanan bu enerjiyi gözlemlemek için, sisteme "şarj" komutu verilmiş, C9 kondansatörünün uçlarındaki sinyal osiloskop ile gözlemlenmiş ve Şekil 9'da verilen görüntü kaydedilmiştir. Şekil 9 incelendiğinde; tahrip gerilim eşiği olarak kabul ettiğimiz $150 \mathrm{~V}$ gerilim seviyesine 5 saniyede, tam skala kapsül ateşleme gerilimi olan $350 \mathrm{~V}$ seviyesine ise 20 saniyede ulaşıldığ görülmektedir. Ayrıca, tam skala kapsül ateşleme gerilimine ulaşıldıktan sonra sinyalin 370V'a 
karşılık gelen A noktası ile 330V'a karşılık gelen B noktaları arasında salındığı ve ortalama gerilimin $350 \mathrm{~V}$ seviyesinde tutulduğu görülmektedir.

Sisteme uygun kapsül bağlantısı yapılmış, "şarj” komutu verilmiş, tahrip gerilim eşiğine ulaşılmış ve şarj komutu ile beraber "imha" komutu verilmişse kapsül ateşlenecektir. Kapsül ateşlemesinden vazgeçilip "şarj” komutu iptal edildiğinde sistem "kapalı" duruma geçer ve C9 kondansatörü, R1 direnci üzerinden deşarj olur. Bu sayede, sistem kapalı durumda iken C9'un yük tutması engellenmiş ve kapsülün tesadüfi ateşlenmesinin önüne geçilmiş olur. "Şarj” komutundan vazgeçilmesi ile birlikte C9 üzerindeki enerjinin deşarjını incelemek için sisteme "şarj" komutu verilmiş, tahrip gerilim eşiğine ulaşıldıktan bir süre sonra "şarj" komutu iptal edilmiş, tüm bu işlemler esnasında C9 kondansatörü uçlarındaki sinyaller osiloskop ile gözlemlenmiş ve Şekil 10'da verilen görüntüler kaydedilmiştir. Şekil 10 (a) ve (b)'de görüldüğü üzere, "şarj” komutunun verilmesi ile birlikte $280 \mathrm{~V}$ seviyesine ulaşıldığı anda "şarj" komutu iptal edilmiş, C9 kondansatörü üzerinde depolanan enerji 200 ms'de tamamen deşarj olmuştur.

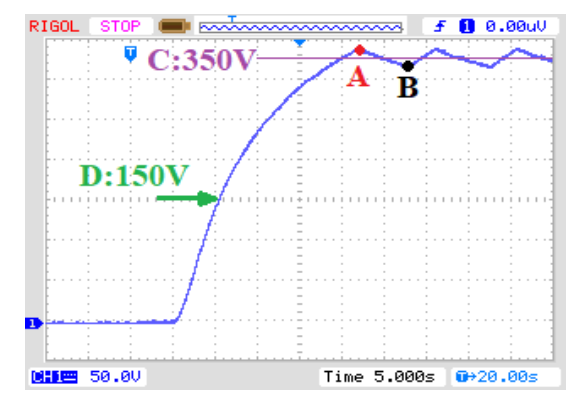

Şekil 9. C9 Kondansatörünün Şarj Eğrisi

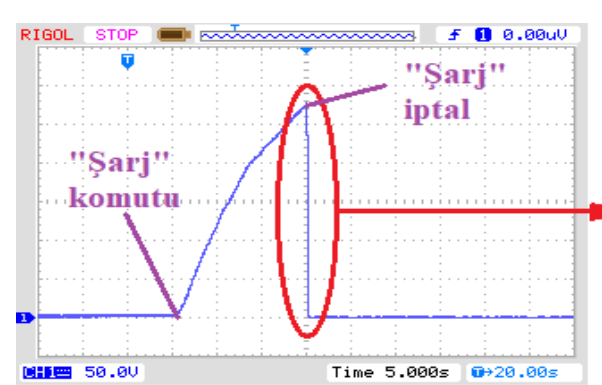

(a)

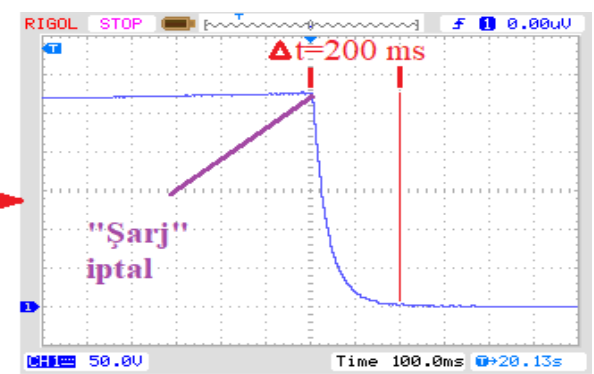

(b)

Şekil 10. "Şarj” Komutunun Verilmesi ve İptali ile Elde Edilen Sinyaller (a) $t / s e c: 5.000 \mathrm{~s}$ kademesi (b) $t / \mathrm{sec}: 100.00 \mathrm{~ms}$ kademesi 


\section{b. Tahrip Performansının İncelenmesi}

Sistemin tahrip performansının incelenmesi için gerçekleştirilen deneylerde, kibritbaşı ve MKEK tarafindan üretilen sınıf-1 elektrikli kapsüle eşdeğer dirençler kullanılmıştır.

$\mathrm{Bu}$ maksatla gerçekleştirilen ilk deneyde bir adet kibritbaşı kullanılmış, sistem tam skala kapsül ateşleme gerilimine şarj edilmiş ve imha işlemi gerçekleştirilmiştir. Bu işlemler esnasında kapsül çıkış noktalarındaki sinyaller osiloskop ile gözlenmiş ve Şekil 11 (a) ve (b)'de verilen görüntüler kaydedilmiştir. Elde edilen sinyaller incelendiğinde, kibritbaşının $25 \mathrm{~ms}$ gibi bir sürede imha olduğu, ardından C9 üzerinde kalan enerjinin 125 ms gibi bir süre sonunda deşarj olduğu görülmektedir.

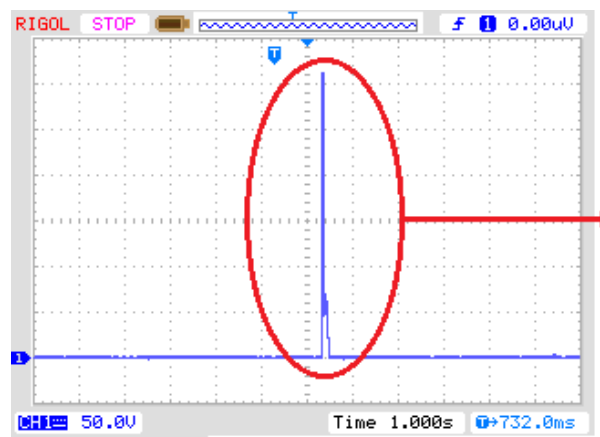

(a)

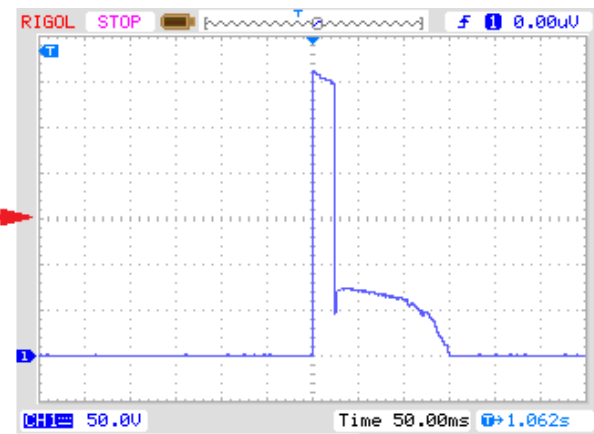

(b)

Şekil 11. Bir Adet Kibritbaşının İmhası Esnasında Elde Edilen Sinyaller (a) t/sec:1.000s kademesi (b) t/sec:50.00ms kademesi

Tahrip performansının incelenmesine yönelik ikinci deneyde, on adet paralel bağlı MKEK sınıf-1 elektrikli kapsüle eşdeğer dirençler kullanılmış, sistem 180V ateşleme gerilimine şarj edilmiş ve imha işlemi gerçekleştirilmiştir. Bu işlemler esnasında kapsül çıkış noktalarındaki sinyaller osiloskop ile gözlenmiş ve Şekil 12 (a) ve (b)'de verilen görüntüler kaydedilmiştir. Elde edilen sinyaller incelendiğinde paralel bağlı yüklerin 580 ms'de imha olduğu, C9 üzerinde kalan enerjinin 120 ms'de deşarj olduğu görülmektedir. 


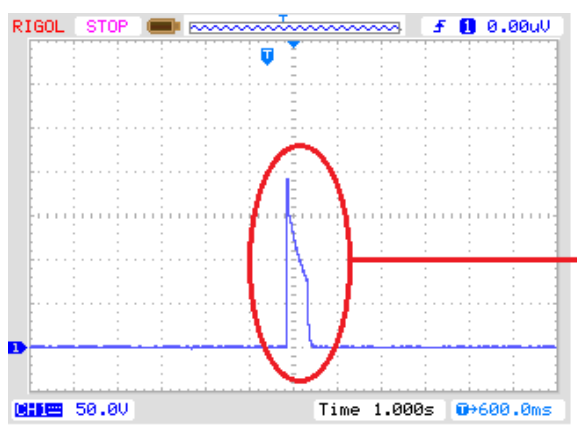

(a)

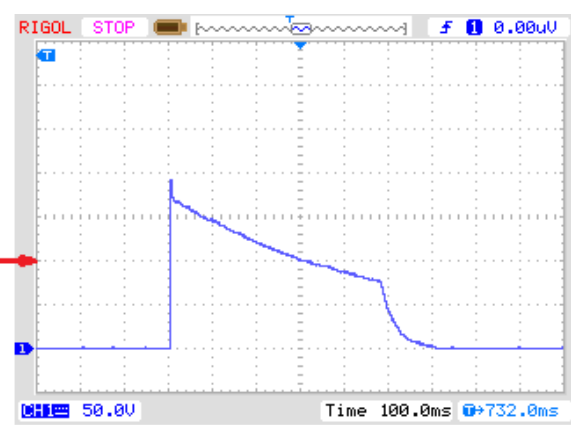

(b)

Şekil 12. On Adet Paralel Bağlı MKEK Sınıf-1 Elektrikli Kapsüle Eşdeğer Dirençlerin İmha Esnasında Elde Edilen Sinyaller (a) t/sec:1,000s Kademesi

(b) t/sec:100,00ms Kademesi

Tahrip performansının incelenmesine yönelik üçüncü deneyde, 250 metre uzunluğunda TS EN 50525-2-31 standartlarında $0,75 \mathrm{~mm}^{2}$ kesitinde kablo çifti ucuna bir adet kibritbaşı bağlanmış, sistem tam skala kapsül ateşleme gerilimine şarj edilmiş ve imha işlemi gerçekleştirilmiştir. Bu işlemler esnasında kapsül çıkış noktalarındaki sinyaller osiloskop ile gözlemlenmiş ve Şekil 13 (a) ve (b)'de verilen görüntüler kaydedilmiştir. Elde edilen sinyaller incelendiğinde 250 metre uzunluğunda kabloya bağlı kibritbaşının 490 ms'de imha olduğu, C9 üzerinde kalan enerjinin 110 ms'de deşarj olduğu görülmektedir.

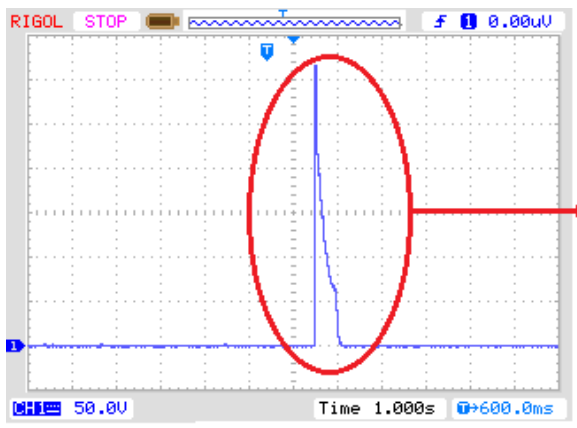

(a)

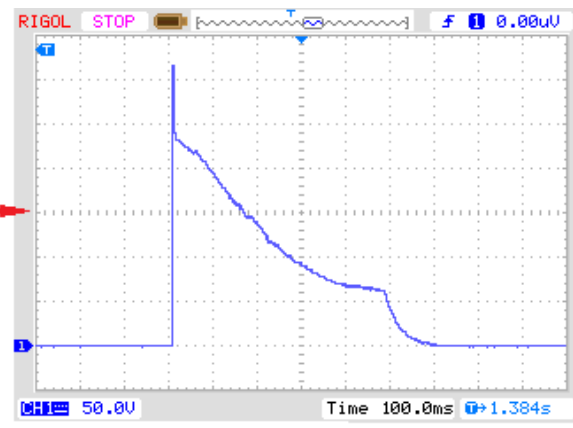

(b)

Şekil 13. 250 Metre Uzunluğunda, TS EN 50525-2-31 Standartlarında, 0,75mm2 Kesitinde Kablo Çifti Ucuna Bağlı Bir Adet Kibritbaşının İmhası Esnasında Elde Edilen Sinyaller (a) t/sec:1,000s Kademesi (b) t/sec:100,00ms Kademesi 


\section{c. Kapsül Direnci Ölçüm Performansının İncelenmesi}

Tahrip işlemi esnasında önemli parametrelerden bir tanesi de toplam kapsül direncidir. Sisteme bağlı kapsüllerin toplam direnci, depolanan enerjinin kapsülleri imha edip edemeyeceğinin bir değerlendirmesinin yapılmasını sağlar. Geliştirilen sistem 0 ile $1 \mathrm{~K} \Omega$ aralığında kapsül direnci ölçülmesine olanak tanır. Sistem performansı incelemelerinde yapılan ölçümler neticesinde, direnç ölçümü esnasında kapsülden 20 ms süre ile $200 \mu \mathrm{A}$ akım geçirildiği görülmüştür. Kapsülden çok kısa bir süreliğine, çok düşük bir akım geçirilerek direnç ölçümü yapılması emniyet açısından çok önemli bir kriterdir.

Geliştirilen sistem tarafindan yapılan direnç ölçümlerinin doğruluğunu tespit etmek için; birinci ölçüm elemanı olarak geliştirdiğimiz sistem, ikinci ölçüm elemanı olarak akredite kuruluş tarafindan kalibre edilen Fluke-116 multimetre, üçüncü ölçüm elemanı olarak akredite kuruluş tarafından kalibre edilen Protek-608 multimetre kullanılmıştır. Değeri bilinen sabit karbon dirençler bir, iki ve üçüncü ölçüm elemanları ile ölçülmüş ve elde edilen direnç değerleri Tablo 3'e kaydedilmiştir. Tablo 3'ten görüleceği üzere; geliştirilen sistem ile yapılan direnç ölçümleri, akredite kurumlar tarafından kalibre edilen ölçü elemanları ile yapılan direnç ölçümleri birbiri ile uyumludur. Geliştirilen sistem ile yapılan direnç ölçümlerinde, ölçülen sabit değerli karbon direnç değerine göre en fazla \%1,06 hata ile ölçüm yapılmıştır. Deney 0-1000 $\Omega$ ölçüm aralığında ve ortalama \%0,77 ölçüm hatası ile gerçekleştirilmiştir. 
Tablo 3. Direnç Ölçüm Sonuçları

\begin{tabular}{|c|c|c|c|c|}
\hline \multirow[b]{2}{*}{$\begin{array}{c}\text { Direnç } \\
\text { Değeri } \\
{[\Omega]}\end{array}$} & \multicolumn{4}{|c|}{$\begin{array}{l}\text { Ölçüm elemanı ile yapılan direnç ölçüm } \\
\text { sonucu }\end{array}$} \\
\hline & $\begin{array}{c}\text { Birinci } \\
\text { Ölçüm } \\
\text { Eleman1 } \\
{[\Omega]}\end{array}$ & $\begin{array}{c}\text { İkinci } \\
\text { Ölçüm } \\
\text { Elemanı } \\
{[\Omega]}\end{array}$ & $\begin{array}{c}\text { İkinci } \\
\text { Ölçüm } \\
\text { Elemanı } \\
{[\Omega]} \\
\end{array}$ & $\begin{array}{c}\text { Ölçüm } \\
\text { Hatas1 } \\
{[\%]}\end{array}$ \\
\hline 1 & 0,99 & 1,01 & 1,00 & 1,00 \\
\hline 4,7 & 4,68 & 4,74 & 4,72 & 0,43 \\
\hline 10 & 9,92 & 10,1 & 10,0 & 0,80 \\
\hline 15 & 14,8 & 15,1 & 15,1 & 1,33 \\
\hline 22 & 21,8 & 22,3 & 22,2 & 0,91 \\
\hline 47 & 46,5 & 47,5 & 47,3 & 1,06 \\
\hline 68 & 67,5 & 68,7 & 68,5 & 0,74 \\
\hline 100 & 99,5 & 101 & 100 & 0,50 \\
\hline 120 & 119 & 121 & 120 & 0,83 \\
\hline 150 & 149 & 151 & 151 & 0,67 \\
\hline 220 & 218 & 222 & 221 & 0,91 \\
\hline 270 & 268 & 272 & 272 & 0,74 \\
\hline 330 & 328 & 333 & 332 & 0,61 \\
\hline 390 & 388 & 394 & 393 & 0,51 \\
\hline 470 & 467 & 474 & 473 & 0,64 \\
\hline 560 & 555 & 565 & 564 & 0,89 \\
\hline 680 & 674 & 686 & 685 & 0,88 \\
\hline 820 & 814 & 829 & 826 & 0,73 \\
\hline 980 & 975 & 983 & 982 & 0,51 \\
\hline
\end{tabular}

\section{Sonuç ve Öneriler}

$\mathrm{Bu}$ çalışma kapsamında, mikrodenetleyici tabanlı bir elektronik kapsül ateşleme sistemi tasarlanmış ve prototip üretimi gerçekleştirilmiştir. Gerçekleştirilen deneysel çalışmalar neticesinde aşağıdaki sonuçlar elde edilmiştir:

Geliştirilen sistem ile toplamda $8 \mathrm{Ws} / \Omega$ enerji seviyesine kadar ateşlemeler gerçekleştirilebilir.

Sistem tekil ateşlemelerin yanı sıra paralel, seri ve karışık bağlantılı ateşlemelerin gerçekleştirilmesine olanak tanır.

0-1000 $\Omega$ aralığında ortalama $\% 0,77$ hata ile direnç ölçümü gerçekleştirilebilir. 
Tam dolu pillerle 700 adet tekil ateşleme gerçekleştirilebilir.

Ateşleme sonunda sistemde kalan enerji kısa sürede deşarj edilerek kapsül emniyeti sağlanmaktadır.

Sistem bekleme durumunda ve şarj komutundan vazgeçme durumunda şarj edilen enerji en fazla 200 ms'de deşarj edilerek kapsül emniyeti sağlanmaktadır.

Ateşleme işleminden önce kapsül kablo bağlantısı, düşük akımlarla elektronik olarak kontrol edilebilir.

Sistem kondansatörü en azından eşik voltaj seviyesine şarj olana kadar ateşleme komutuna izin verilmez.

Elde edilen sonuçlar incelendiğinde, özellikle EOD timleri tarafından kullanılabilecek bir sistem geliştirildiği değerlendirilmektedir.

Batarya teknolojilerindeki gelişmeler izlenerek art arda ateşleme sayısı daha fazla olan bir sistem geliştirmek mümkün olabilir. Ayrıca bu çalışmada ortaya konan sistem tasarım ilkeleri esas alınarak, kablosuz bir ateşleme sistemi geliştirmek mümkün olabilir.

\section{Extended Summary}

Explosives are chemical substances that can turn into gas from a solid-state in a very short time and can create physical effects in the environment with high amounts of heat, shock, and sound during this transition. They are used in many civilian and military fields such as mining operations, destruction works in large structures, opening passageways, and destroying specified targets.

Detonator is a term used in the explosive industry to describe the device used to initiate an explosion. Different types of detonators can be used to activate explosives in applications. They are classified as class-1, class-2, and class-3 and are also named as "sensitive", "insensitive", and "very insensitive", respectively.

Electric detonators are igniters with a matchhead inside that can be stimulated electrically. A battery can be used as the energy source to ignite the electric detonators, and Electric Detonator Ignition Systems (EDIS) are preferred for sequential and safe ignitions. The most important feature expected from a reliable 
EDIS is that it must provide the required current and energy ratings outside of the unsafe range.

EDISs allow ignition with more than one electrical detonator in serial, parallel, or mixed connections. In EDIS, the ignition pulse energy to be applied to the detonator is primarily stored in a capacitor, and this energy is discharged inside the detonator at the desired moment, and the explosion is realized. During energy storage, no current should flow through the detonator, and accident prevention measures should be taken.

The proposed system has been designed by taking into account the safety limits of the detonators, unstable operating points, and operator safety. The system uses DC voltage from three serially connected $1.5 \mathrm{~V}$ lithium batteries as the supply source. The supply circuit consists of a non-insulated step-up DC-DC converter and a fixed DC-DC converter.

Atmega328 microcontroller has been chosen as the central processing unit (MIB) in order to control the data flow in all units in the system. The microcontroller has some main tasks, such as processing commands from the keypad and creating function images on the OLED screen of the user interface, communicating with an analog-to-digital converter (ADC) to measure the detonator resistance, and generating a pulse-width modulated (PWM) signal for detonator ignition.

Wheatstone bridge, DC-DC power converter, and power driver are the units in which the detonator resistance is tested. The energy required for ignition is obtained, and the destruction of the detonator is performed with a command given, respectively.

Some experimental studies have been carried out in order to examine the functions and performance of the developed prototype system. Matchheads and resistors were used in the experiments to examine the destruction performance of the system. Three different experiments were conducted for this purpose, and in all these experiments, destruction, charge and discharge periods, maximum and instant charge voltages were measured and observed with an oscilloscope. In order to evaluate the resistance measurement performance of the system and compare the results with each other, two different digital resistance measurement devices were also used together. 
As a result of the experimental studies carried out, the following results have been obtained. Ignitions up to $8 \mathrm{Ws} / \Omega$ energy level can be realized in a single operation. It is possible to perform igniting in parallel, serial, and mixed connections. Detonator Resistance can be measured with an average error of $0.77 \%$ in the range $0-1000 \Omega$. Up to 700 individual ignitions can be performed with 3 AA fully-charged lithium batteries. At the end of the ignition, the remaining energy in the system is discharged in a short time, and detonator safety is provided. If the "Charge" command is canceled, the capacitor is discharged within $200 \mathrm{~ms}$ at most, ensuring detonator safety. The detonator wiring can be electronically checked before igniting. No ignition command is allowed until the system capacitor is charged to at least the threshold voltage level. When the obtained results are examined, it is evaluated that a system that can be used by EOD teams has been developed.

\section{Kaynakça}

\section{Kitaplar}

Beveridge, A. D. (2013). Improvised Explosive Devices. Academic Press, Waltham.

Konya, Calvin J. (1995). Blast Design. Intercontinental Development Corporation, Ohio, U.S.A.

Zhang, Zong-Xian. (2016). Explosives and Detonators. Butterworth-Heinemann.

\section{Makaleler}

Bickes Jr., R. W. (1996). Explosive Systems Utilizing Semiconductor Bridge, SCB, Technology. Propellants, Explosives, Pyrotechnics, 21(3), 146-49.

Jadhav, P.Y. ve Rajendrakumar A.P. (2016). Mechanism of Electronic Delay Device for Detonator. International Journal of Innovative Research in Science, Engineering and Technology, 5(5), 8640-51.

Özdikmen, T. (2009). Terör Amaçlı Kullanılan Patlayıcılar, Etkileri ve Alınacak Önlemler. Adli Bilimler Dergisi, 8(3), 72-75.

Pande, J., Virendra, K. ve Archana S. (2015). Electronic SCB Delay Detonator System for Mines. International Journal of Electrical, Electronics and Data Communication, (Special Issue-1), 131-35. 
Solov'ev, V. O., Ovchinnikov, N. M., Patsyuk, V.V. ve Lavrov, V. V. (2015). A New Generation of Special Electric Detonators. Journal of Machinery Manufacture and Reliability, 44(8):726-36.

\section{Tezler}

Özcan, E. (2006). Kesme Tekniklerinde Kullanılan Doğrusal Boşluklu Patlayıcı Kaplarında Optimum Ayak Mesafelerinin Araştırılması. (Yayımlanmamış Yüksek Lisans Tezi). Ankara Üniversitesi, Sağlık Bilimleri Enstitüsü, Ankara.

\section{Web Kaynakları}

Detomax. (2020). Advanced Initiation Systems". http://www.epsilonndt.com/images/urunbelgeleri/detomax_jk_ne_v1_72d17.pdf adresinden alınmıştır.

Kılıç, Ü. ve Bağcaz, A.T. (2015). Elektrikli Kapsüllerin Güvenli Olarak Ateşlenmesi İçin Bazı Detaylar. http://www.madser.com.tr/dosyalar/ElektrikliKapsullerin-Guvenli-Olarak-Ateslenmesi-Icin-Bazi-Detaylar.pdf adresinden alınmıştır.

MINI-SHRIKE. (2018). Single Output Handheld Exploder. https://www.chemring.co.uk/ /media/Files/C/Chemring-V3/documents/ sensors/cts18-mini-shrike-03128-v10.pdf adresinden alınmıştır.

MKEK. (2020). Alüminyum Elektrikli https://www.mkek.gov.tr/tr/product.aspx ?id=52\&source=products\&pid=110 4adresinden alınmıştır.

PED-MK2. (2018). A Timer Based Programmable Initiator. https://www.chemring.co.uk/ /media/Files/C/Chemring-V3/documents/ sensors/03189-ped-mk2-datash.pdf adresinden alınmıştır. 